\title{
Water desalination using a temperature gradient
}

\author{
John Robinson*, Joseph Meehan, Ali Taqi, Eleanor Binner, Begum Tokay \\ Faculty of Engineering, University of Nottingham. NG7 2RD. UK
}

\begin{abstract}
A new concept for reverse osmosis is identified based on the use of a temperature gradient instead of pressure. When the temperature of the permeate-side of the membrane is higher than the feed-side then a significant driving force exists for water transport, which can overcome the osmotic pressure. The thermodynamics for this approach are developed within the paper, and as a result we have developed a single expression for driving force across a membrane for variable temperature, pressure and concentration. The thermodynamic predictions suggest for seawater a temperature difference of less than $1^{\circ} \mathrm{C}$ is needed to overcome the osmotic pressure, and less than $3^{\circ} \mathrm{C}$ to sustain a water flux equivalent to current reverse osmosis processes. Experimental investigation confirmed the temperature-dependence of water flux and the ability to carry out reverse osmosis at atmospheric pressure. The effect of temperature gradient and salinity on water flux was tested at ambient pressures and found to be in good agreement with the manufacturer-quoted permeability. The concept identified in this work has the potential to allow reverse osmosis to be carried out without the need for costly high pressure pumps and energy recovery systems, with energy requirements predicted to be lower than $2.0 \mathrm{kWh} / \mathrm{m}^{3}$.
\end{abstract}

\section{Keywords}

Temperature; reverse osmosis; membrane; low energy

\section{Introduction}

Water scarcity is one of the major global challenges. For many countries their current water resources are not adequate due to rapid population growth and industrialisation. In addition, natural water supplies are decreasing due to climate change and over exploitation. Today around 700 million people in 43 countries suffer from water scarcity [1]. By 2025, 1.8 billion people are expected to be living in countries or regions with absolute water scarcity, and two-thirds of the world population could be under water stress conditions [2]. Desalination of brackish or seawater has emerged as a solution to deal with the growing demand for good quality water that complies with Drinking Water Inspectorate standards for both drinking and irrigation [3]. At present, reverse osmosis (RO) is the leading 
technology and responsible for producing more than half of the world's desalination capacity owing to its ability to reject the smallest contaminants and monovalent ions [4]. The total global desalination capacity of RO reached 67 million $\mathrm{m}^{3} /$ day in 2011 [5].

RO technology is attractive commercially because of the continuous advances in membrane development, module and process design and energy recovery. However, not every nation can fund widespread provision of drinking water to dry areas using RO, due to the high energy, operational and capital costs. Although the process requires only $25 \%$ more energy than the thermodynamic limit [6], RO membranes process water at limited rates, requiring large capital-intensive plants to produce a sufficient flow.

\section{Overview of RO desalination}

Osmosis is a phenomenon where pure water flows from a dilute solution through a semi permeable membrane to a more concentrated solution [7]. Applying an external pressure to reverse the natural flow of water is termed as reverse osmosis (Figure 1). Before entering the RO membrane unit, clarified saline water is pressurised by the pressure pumps to between 55-85 bar. The pressure required increases with water salinity in order to overcome the osmotic pressure. The permeate stream has a low salt concentration, typically leaving $95-99 \%$ of dissolved salts in the retentate stream. The separation system typically comprises a number of membrane elements arranged in series [8]. The pressure drop across the system between feed and retentate is around 2 bar, so the outlet with high salt concentration is released at high pressure. Energy from the concentrate flow can be reused via energy recovery devices such as an energy recovery turbine (ERT) and pressure exchanger (PX), which transfer the energy of the concentrate directly to a part of the incoming feed water. These devices typically allow energy recoveries of $30-40 \%$ (ERT) and 50-60\% (PX) [9].

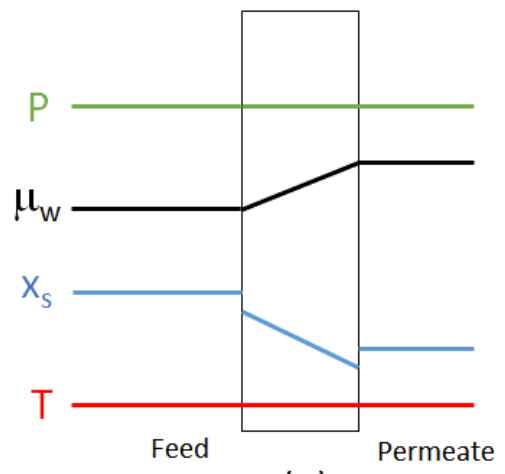

(a)

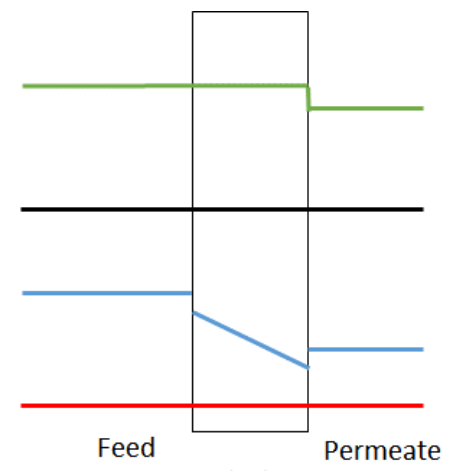

(b)

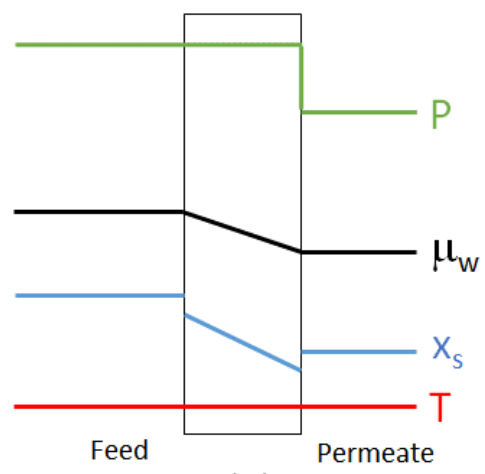

(c)

Figure 1 - Temperature $(T)$, water chemical potential $\left(\mu_{w}\right)$, solute concentration $\left(x_{s}\right)$ and pressure $(P)$ across the active membrane layer for three cases of pressure-driven mass transfer; (a) forward osmosis, (b) osmotic equilibrium, (c) reverse osmosis 
Polymeric membranes are most commonly used for RO desalination. They comprise a thin (0.1-10 $\mu \mathrm{m})$ active layer, which is a dense polymer that provides the main resistance to salt mass transfer [7]. The pressure drop across this thin layer can be of the order of 50-80 bar, so a composite material is needed to allow the thin active layer to withstand such pressures. The active layer is typically formed on the surface of a porous support layer, which in turn is impregnated within a fibrous material (typically cellulose or glass fibres) to provide the mechanical strength needed to support a large pressure drop. The composite membrane is then formed or wound into different configurations depending on the required surface area and pressure drop, and contained within a modular housing. Multiple modules are employed in parallel to meet the overall surface area requirement of the separation process.

\section{Current status}

Today, RO is the leading desalination technology, overtaking conventional multi-stage flash and new technologies such as electrodialysis, and forward osmosis [10]. In industry, RO is used for the production of ultra-pure water for the electronic, pharmaceutical, food and energy production processes. The Middle East and North Africa region has become a focal point for seawater desalination plants as a result of continued fresh water shortages due to low annual rainfall, combined with its geological characteristics [11]. Although advances in membrane materials and energy recovery over the last 30 years has reduced the energy cost to between 3.5-4.0 $\mathrm{kWh}$ per $\mathrm{m}^{3}$ of produced water [12], electricity is still the major variable cost (41\%) when compared to capital investment cost (14\%).

Current research on RO desalination is centred on improvements in membrane morphology to increase permeability, selectivity and stability and to reduce replacement cost. Examples include the incorporation of nanoparticles into the thin active layer to enhance the membrane selectivity [13], modification of the membrane surface with organic surfactants to reduce fouling [14], and the hydrodynamic design of modular elements to increase capacity with reduced concentration polarisation and fouling [15]. 


\section{Challenges/limitations with the technology}

Recent technological developments have reduced the unit cost of clean water, however these improvements inevitably come at the expense of capital cost. Energy recovery must be maximised to lower the operational cost of RO plants, which requires capital investment in ERT or PX systems. Membranes must be purchased that can handle high pressure while providing high salt rejection, high water flux and reduced fouling, however these highly-engineered materials add extra burden to the capital and operational cost. One of the largest RO plant in the world (624 million $\mathrm{m}^{3} / \mathrm{year}$ ) can only supply fresh water to less than 2 million people [16]. Using current desalination technology to provide clean water to millions requires numerous process plants and significant capital investment. The overall affordability of RO for poorer countries is still a major barrier [17].

\section{Alternative Processes}

Forward osmosis (FO) is an alternative desalination processes that exploits a difference in concentration rather than pressure [18]. A second solute is added to the solution on the permeate side to reduce the water chemical potential, allowing water flow from the salt-water side to the permeate [19]. Thus, FO requires less energy to transport a net water flow across the membrane when compared to RO as no pressure is needed, however the added solute must be extracted from the permeate by means of a second separation step. This can add significantly to the energy costs depending on the solute and the recycling process [20]. McGovern and Lienhard showed that the actual energy consumption of $\mathrm{FO}\left(3.58 \mathrm{kWh} / \mathrm{m}^{3}\right)$ is higher than 2-pass RO $\left(3.00 \mathrm{kWh} / \mathrm{m}^{3}\right)$ if $\mathrm{RO}$ and the draw regeneration process operate at the same efficiency [21]. The secondary separation step within FO therefore negates the advantage of the primary low-pressure process, and to-date FO is not a commercially-viable option.

Harvesting water from air to produce drinking water has attracted attention as an alternative technology to desalination. Water vapour in the air is condensed by cooling the air below its dew point or exposing the air to desiccants. The atmosphere not only contains 13 trillion $\mathrm{m}^{3}$ water, but it is also free from bacteria and solutes. If it can be harnessed then this natural resource could address the global water supply problem [22]. Existing harvesting systems use electrical compression-expansion refrigeration units to cools the air. This lowers the air temperature to its dew point, causing water to condense. However the energy demand of water harvesting using this method exceeds that of RO [23]. Desiccants can be used to absorb/adsorb water vapour with very low energy requirements, however a secondary separation step is required to produce pure water from the desiccant and this 
results in net energy requirements that are comparable to the compression/expansion cooling process.

\section{Hypothesis and Objectives}

This work reports an alternative, atmospheric pressure desalination concept that is based on the use of a small temperature gradient across a membrane to alter the mass transfer characteristics. The principle of temperature-driven RO is derived from work carried out by Lee et al. [24], who investigated the effects of thermal gradients on mass transfer during microwave heating. They identified that a chemical potential gradient could be enhanced if a temperature-difference could be sustained across a cellular membrane, which in turn leads to higher rates of water diffusion. In the case of a temperature gradient, chemical potential decreases as temperature increases. The application of this effect to desalination is depicted in Figure 2.

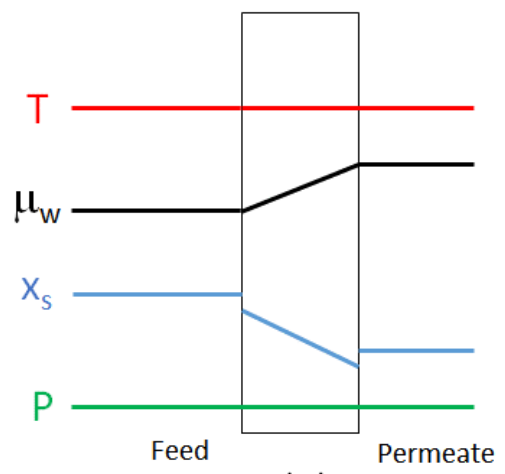

(a)

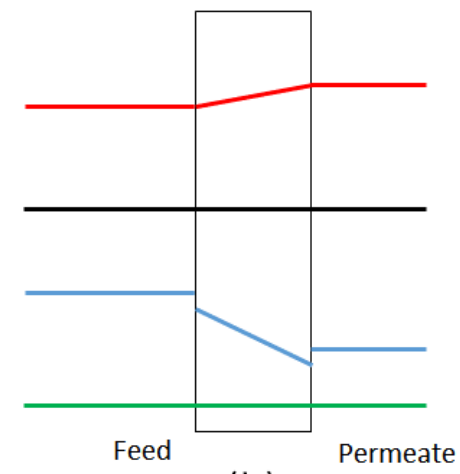

(b)

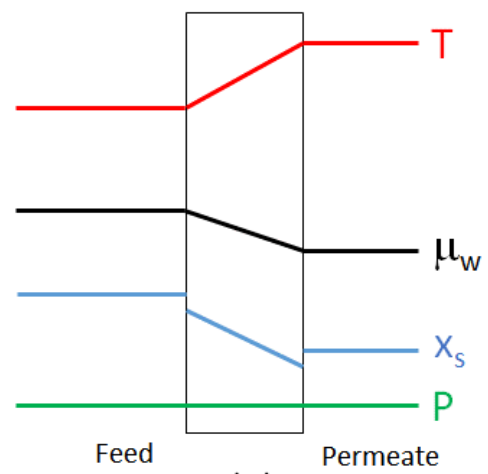

(c)

Figure 2 - Temperature $(T)$, water chemical potential $(\mu \mathrm{w})$, solute concentration $\left(X_{S}\right)$ and pressure $(P)$ across the active membrane layer for three cases of temperature-driven mass transfer; (a) forward osmosis, (b) osmotic equilibrium, (c) reverse osmosis

At constant temperature and constant pressure (a) there is a chemical potential gradient for water from the permeate side to the salt-water side, which results in water diffusion by osmosis. If the purewater side of the membrane is maintained at a higher temperature than the salt-water side then the chemical potential gradient for water transport reduces, leading to less water diffusion. Osmotic equilibrium can be achieved at a threshold temperature, where the chemical potential of water is equal on each side of the membrane (b). If the permeate-side temperature is increased further then a chemical potential gradient is created in the opposite direction, leading to reverse osmosis (c). The system shown in Figure 2 applies when both feed and permeate are in the liquid phase. In cases where membrane distillation is used then the phase change has a significant effect on the chemical potential and the subsequent mass transfer driving force across the membrane. 
The original study by Lee et al. [24] showed that for cellular systems a temperature difference of just $1^{\circ} \mathrm{C}$ was equivalent to a pressure difference of over $30 \mathrm{bar}$. A large pressure is needed to affect a relatively small change in chemical potential due to the incompressibility of water, whereas temperature has a more direct influence on chemical potential. If the same theory applies to desalination then instead of membranes operating at 55-85 bar, a temperature difference of around $2^{\circ} \mathrm{C}$ could have achieve the same effect. This could enable desalination to occur without the need for capital-intensive pumps, membrane housings and energy-recovery systems, and ultimately lower or remove the barriers that make RO unaffordable for low-income countries. The aim of this study is to develop and test the temperature-driven reverse osmosis theory, conduct experimental validation, identify the likely energy requirements and the opportunities and limitations for further technology development.

\section{Temperature-driven reverse osmosis: theoretical development}

The change in chemical potential $(\mu)$ across a membrane can be expressed for simultaneous changes in pressure, temperature and concentration. A mathematical expression for the relationship can be obtained by considering each variable sequentially, e.g. by considering the change in pressure $(P)$ at constant temperature $(T)$ and composition, then the change in $T$ at constant composition and $P$, and finally the change in composition at constant $P \& T$.

$d \mu=\left(\frac{\partial \mu}{\partial P}\right)_{T_{1}, a_{1}} d P+\left(\frac{\partial \mu}{\partial T}\right)_{P_{2}, a_{1}} d T+\left(\frac{\partial \mu}{\partial a}\right)_{P_{2}, T_{2}} d a$

Where $a$ is the activity, used here in place of concentration as it can be applied universally to nonideal mixtures. Subscripts $1 \& 2$ denote different sides of the active layer of the membrane. The partial derivatives in Equation 1 can be substituted with appropriate relationships from the thermodynamic network [25] to yield:

$d \mu=v d P-s d T+\frac{R T}{a} d a$

Where $v$ is the molar volume and $s$ is the entropy. Equation 2 can subsequently be integrated to give the change in chemical potential from $\left(T_{1}, P_{1}, a_{1}\right)$ to $\left(T_{2}, P_{2}, a_{2}\right)$ :

$\Delta \mu=\mu_{2}-\mu_{1}=\int_{P_{1}}^{P_{2}} v d P-\int_{T_{1}}^{T_{2}} s d T+R T_{2} \int_{a_{1}}^{a_{2}} \frac{1}{a} d a$ 
From Equation 3 the three terms on the RHS can be developed separately. The $d P$ term can be developed using the ideal gas law, but with the pressure term replaced by fugacity in order to account for non-ideal behaviour and a liquid phase. Integration then yields:

$\int_{P_{1}}^{P_{2}} v d P=R T_{1} \ln \left(\frac{\widehat{f}_{2}}{\widehat{f}_{1}}\right)$

Where $\hat{f}$ is the fugacity within a mixture, and can be related to the fugacity of the pure substance at the mixture conditions according to Equation 5:

$\hat{f}=a f$

For liquids, the fugacity can be related to the value at saturation by Equation 6 :

$\ln f=\ln f^{*}+\frac{v}{R T}\left(P-p^{*}\right)$

At constant activity $\left(a_{1}\right)$ and temperature $\left(T_{1}\right)$, the combination of Equations $4,5 \& 6$ gives:

$\int_{P_{1}}^{P_{2}} v d P=v\left(P_{2}-P_{1}\right)$

In this case $v$ is a constant as liquids are incompressible, and the value used within Equation is the molar volume at $T_{1}$. The $d T$ term in Equation 3 can be expanded based on entropy as a function of temperature, as defined by Equation 8:

$s=s^{0}+\int_{T_{1}}^{T_{2}} \frac{c_{p}}{T} d T$

Where $s^{0}$ is the entropy of the pure substance at $T_{1}$. By definition, for a pure substance this quantity equates to the entropy of formation. $c_{p}$ is the specific heat capacity. Integrating Equation 8 therefore gives:

$\int_{T_{1}}^{T_{2}} S d T=\int_{T_{1}}^{T_{2}}\left[S^{0}+\int_{T_{1}}^{T_{2}} \frac{c_{p}}{T} d T\right] d T$

$s^{0}$ is a constant, and for relatively small changes in temperature $c_{p}$ can also be assumed to be a constant when the substance in question is a liquid. Equation 9 can therefore be integrated between $T_{1}$ and $T_{2}$ to give:

$\int_{T_{1}}^{T_{2}} s d T=s^{0}\left(T_{2}-T_{1}\right)-c_{p}\left(T_{2}-T_{1}\right)+c_{p} T_{2} \ln \left(\frac{T_{2}}{T_{1}}\right)$

For small changes in temperature the $T_{2} \ln \left(\frac{T_{2}}{T_{1}}\right)$ term in Equation 10 approximates to $\left(T_{2}-T_{1}\right)$, giving the final expression: 
$\int_{T_{1}}^{T_{2}} s d T=s^{0}\left(T_{2}-T_{1}\right)$

The $d a$ term in Equation 3 can be integrated directly to give:

$R T_{2} \int_{a_{1}}^{a_{2}} \frac{1}{a} d a=R T_{2} \ln \left(\frac{a_{2}}{a_{1}}\right)$

Substituting the integrated $d P$ (Equation 7), $d T$ (Equation 11) and $d a$ (Equation 12) terms into Equation 3 gives the final expression for a change in chemical potential with simultaneous changes in pressure, temperature and composition:

$\mu_{2}-\mu_{1}=v\left(P_{2}-P_{1}\right)-s^{0}\left(T_{2}-T_{1}\right)+R T_{2} \ln \left(\frac{a_{2}}{a_{1}}\right)$

In the above equation the values for $v$ and $s^{0}$ are those that correspond to $T_{1}$, whilst the activities $a_{2}$ and $a_{1}$ are those that correspond to $T_{2}$. Equation 3 can be rearranged such that the $d P, d T$ and $d a$ components are solved in a different order, however for relatively small changes in temperature $v, s^{0}$, $a_{2}$ and $a_{1}$ will not vary significantly. For example, a $2^{\circ} \mathrm{C}$ variation in temperature affects $v, s$ and $a$ in liquid water as shown in Table 1.

\begin{tabular}{|l|l|}
\hline Parameter & \% Variation \\
\hline Molar volume, $v$ & 0.48 \\
\hline Entropy, $s$ & 2.0 \\
\hline Activity, a & 1.1 \\
\hline
\end{tabular}

Table 1 - Effect of temperature rise from $20-22^{\circ} \mathrm{C}$ on molar volume, entropy and activity of a $1 \mathrm{~g} / \mathrm{L} \mathrm{NaCl}$ solution $[26,27]$.

\section{Osmotic Pressure and Membrane flux implications}

Case (b) in Figure 2 shows how a temperature gradient can be used to achieve osmotic equilibrium when there is a concentration difference across the membrane. In qualitative terms, a higher temperature on the pure-water side can achieve osmotic equilibrium in the same way as a higher pressure on the salt-water side. Equation 13 allows this effect to be quantified when pressure, temperature and composition vary simultaneously. At osmotic equilibrium $\Delta \mu=0$, so when the pressure is constant:

$s^{0}\left(T_{2}-T_{1}\right)=R T_{2} \ln \left(\frac{a_{2}}{a_{1}}\right)$

Equation 14 shows the temperature difference needed to produce zero water flux when the activity differs between feed and permeate, and is analogous to the osmotic pressure. Equation 13 can also be used to predict the driving force created by a temperature gradient when the osmotic effect is 
overcome. In this case the overall driving force will be in the form of $\Delta \mu$, but to compare with published data it can be equated to an equivalent pressure driving force $\left(\Delta P_{\text {eqv }}\right)$ that exists over and above the osmotic pressure.

$\Delta P_{e q v}=P-\Pi=\frac{\Delta \mu}{v}$

\begin{tabular}{|c|c|c|c|c|}
\hline & & & Temperatu & Difference \\
\hline $\begin{array}{c}\mathrm{NaCl} \\
\text { concentration }(\mathrm{g} / \mathrm{L})\end{array}$ & $\begin{array}{c}\text { Osmotic } \\
\text { pressure (bar) }\end{array}$ & $\begin{array}{l}\text { water } \\
\text { activity }\end{array}$ & $\begin{array}{l}\text { (1) overcome osmotic } \\
\text { pressure }\left({ }^{\circ} \mathrm{C}\right)\end{array}$ & $\begin{array}{l}\text { (2) equivalent driving } \\
\text { force of } 30 \text { bar }\left({ }^{\circ} \mathrm{C}\right)\end{array}$ \\
\hline 5 & 3.6 & 0.997 & 0.093 & 0.865 \\
\hline 10 & 7.2 & 0.995 & 0.185 & 0.958 \\
\hline 35 & 25.1 & 0.982 & 0.647 & 1.419 \\
\hline
\end{tabular}

Table 2 - Theoretical temperature gradients needed to (1) overcome osmotic pressure (from Equation 14) and (2) achieve the equivalent of 30 bar driving force for three different water salinities (from Equation 15).

Table 2 shows the temperature differences needed to overcome the osmotic pressure for three different values of water salinity, with the system maintained at atmospheric pressure. At $5 \mathrm{~g} / \mathrm{L}$ a temperature difference of $0.1^{\circ} \mathrm{C}$ is sufficient to overcome the osmotic pressure, whereas for concentrations approaching that of seawater $(35 \mathrm{~g} / \mathrm{L})$ the permeate would need to be $0.65{ }^{\circ} \mathrm{C}$ hotter than the feed in order for the osmotic pressure to be overcome. This temperature difference is relatively small, yet consistent with the underlying thermodynamics. Due to the incompressibility of liquid water, a large pressure gradient is needed to increase the chemical potential to balance the effect of the solute, whereas the chemical potential gradient can be manipulated much more readily by small changes in temperature. When the permeate-side temperature is increased further, beyond the value that balances the osmotic pressure, then a driving-force is created for reverse osmosis. Table 2 shows the temperature difference required to achieve a driving force $(P-\Pi)$ equivalent to $30 \mathrm{bar}$. At $5 \mathrm{~g} / \mathrm{L}$ this driving force can be achieved with a temperature gradient of less than $1^{\circ} \mathrm{C}$, whereas for seawater a temperature difference of around $1.5^{\circ} \mathrm{C}$ would be required.

\section{Energy Requirements}

The concept suggests that reverse osmosis will occur spontaneously provided that a sufficient temperature gradient can be sustained between permeate and feed. In practice, this means that water molecules must diffuse from a low-temperature region on the feed-side of a membrane to a highertemperature region on the permeate side. The sensible heat lost during this mass transfer must therefore be replaced in order for the process to proceed spontaneously. Heat must therefore be provided to the permeate side, and flow across the membrane to the feed-side. The minimum energy required to achieve and maintain this temperature gradient is therefore the energy needed to heat 
the permeating water from one temperature to the other, assuming that there are no further conductive or convective heat-losses within the system. This gives a power per unit area for a given combination of temperature difference and water flux:

Minimum Power Flux $=$ Mass Flux $\times c_{p} \times \Delta T$

For relatively small changes in temperature this can be calculated using a constant value of heat capacity, in this case taken as $4.2 \mathrm{~kJ} / \mathrm{kg} . \mathrm{K}$. Minimum energy requirements can then be estimated from the power per unit area and the water flux. The corresponding energy requirement per unit mass of permeate can be established:

Minimum Energy $=\frac{\text { Minimum Power Flux }}{\text { Mass Flux }}=c_{p} \Delta T$

From Equation 17, the energy required is solely a function of heat capacity and temperature difference. Energy does not require flux as a dependent variable, which may seem counter-intuitive however the dependent variable in this case is temperature, which in turn dictates flux. From Equation 13 , increasing the temperature gradient results in an increase in the driving force for mass transfer, which will require more power and result in a higher flux. It is here that the flux-dependency of the energy requirement is contained. Presenting minimum energy requirements based on flux is not appropriate in this case given that they are independent. Instead, the energy requirements can be established based on the temperature gradient needed to produce a certain chemical potential driving force (Equation 13) for a given salt concentration. This may be thermodynamically correct, but it does not allow for ready comparison with conventional membrane separation processes that use a pressure difference to create the driving force. From Equation 15, a defined salt concentration and pressure driving force can be used to establish the corresponding temperature gradient to achieve the same chemical potential. The energy required follows from Equation 17. The minimum energy requirements calculated in this manner for pressure driving forces of $10,30 \& 50$ bar and example water salinities of 5, 10 and $35 \mathrm{~g} / \mathrm{L}$ are shown in Table 3, and expressed per unit volume of permeate.

\begin{tabular}{|c|c|c|c|c|c|c|}
\hline \multirow{3}{*}{$\begin{array}{c}\mathrm{NaCl} \\
\text { concentration }\end{array}$} & \multicolumn{6}{|c|}{ Equivalent Driving Force (bar) } \\
\hline & \multicolumn{2}{|r|}{10} & \multicolumn{2}{|r|}{30} & \multicolumn{2}{|r|}{50} \\
\hline & $\Delta \mathrm{T}$ & $\begin{array}{c}\text { Energy } \\
\text { requirement }\end{array}$ & $\Delta \mathrm{T}$ & $\begin{array}{l}\text { Energy } \\
\text { requirement }\end{array}$ & $\Delta \mathrm{T}$ & $\begin{array}{l}\text { Energy } \\
\text { requirement }\end{array}$ \\
\hline $\mathrm{g} / \mathrm{L}$ & ${ }^{\circ} \mathrm{C}$ & $\mathrm{kWh} / \mathrm{m}^{3}$ & ${ }^{\circ} \mathrm{C}$ & $\mathrm{kWh} / \mathrm{m}^{3}$ & ${ }^{\circ} \mathrm{C}$ & $\mathrm{kWh} / \mathrm{m}^{3}$ \\
\hline 5 & 0.350 & 0.41 & 0.865 & 1.01 & 1.381 & 1.61 \\
\hline 10 & 0.443 & 0.52 & 0.958 & 1.12 & 1.473 & 1.72 \\
\hline 35 & 0.904 & 1.05 & 1.419 & 1.66 & 1.934 & 2.26 \\
\hline
\end{tabular}

Table 3 - Minimum energy requirement for reverse-osmosis using a temperature gradient for three cases of equivalent pressure driving force and three salinity levels. 
The energy required to sustain the temperature gradient for reverse osmosis is dependent upon the required permeate temperature, which in turn is a function of the water salinity and the required driving force. For example, when the equivalent driving force is as low as 10 bar and salinity is $5 \mathrm{~g} / \mathrm{L}$ then the minimum energy requirements can be as low as $0.41 \mathrm{kWh} / \mathrm{m}^{3}$. This corresponds to a temperature difference of just $0.35^{\circ} \mathrm{C}$. If higher water fluxes are required from high salinity water then the temperature difference and subsequent energy requirement increases. For an equivalent 50 bar driving force and salinity of $35 \mathrm{~g} / \mathrm{L}$ the temperature difference increases to $1.934^{\circ} \mathrm{C}$ and minimum energy requirement increases to $2.26 \mathrm{kWh} / \mathrm{m}^{3}$. The calculated energy requirements in this case are comfortably below the $3.5-4.0 \mathrm{kWh} / \mathrm{m}^{3}$ levels exhibited by industrial desalination systems [12]. Whilst not a true like-for-like comparison, the calculated energy requirements suggest that the concept itself cannot be ruled out solely from an energy use perspective. Indeed, if a temperature-driven reverse osmosis system were to be developed that can minimise heat losses beyond those inherently required for mass transfer then clearly this novel technology approach will be competitive with current technologies on energy use, but with the added advantages of operating at ambient pressure. Further discussion on the feasibility of controlling heat loss can be found at the end of the paper.

\section{Experimental Validation}

The theoretical principle was tested by establishing the flux through a commercially-available reverse osmosis membrane with a temperature gradient sustained between permeate and feed. The experimental setup is not intended to mimic an industrial scale system, but has the specific objective of testing the hypothesis that reverse osmosis can be achieved by using a small temperature gradient. A polyamide membrane (DOW Filmtec SW3OHR) was used in flat-sheet form. The membrane was cut into a disc, and clamped between the flanges of two sections of 4" polypropylene pipe to give a wetted diameter of $90 \mathrm{~mm}$. The non-flanged ends of the pipe were sealed, and connected to hot and cold reservoir systems as shown in Figure 3. The hot water side contained inlet and outlet connections for water to be pumped from a heated tank, and circulated through the membrane housing. This is the pure-water side of the system. The salt-water side contained no heating system, but was connected to a header tank to ensure the membrane housing was always full of liquid and with minimal pressure head between the two sides. The entire membrane housing was immersed in cold-water to act as a heat-sink, and to ensure a sufficient temperature gradient was maintained across the membrane. The measured temperature difference $(\Delta T)$ across the membrane varied by $\pm 1.0^{\circ} \mathrm{C}$ over the course of each experiment, so the minimum $\Delta T$ that could be reliably obtained with this system was $1.5^{\circ} \mathrm{C}$. 


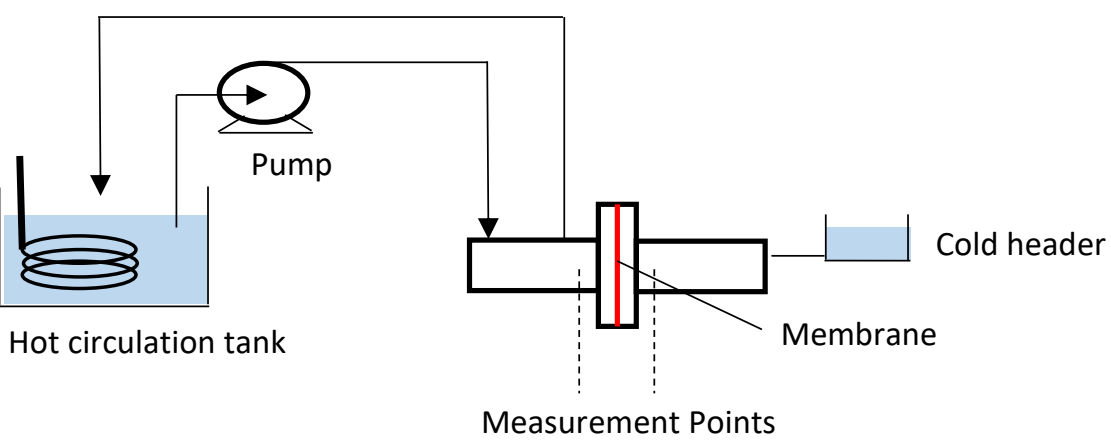

Figure 3 - Schematic of temperature-driven reverse osmosis system for proof-of-principle

The salt-water side was charged with an initial volume of 5 litres. Temperature and conductivity measurements were made at the measuring points on either side of the membrane. Conductivity was measured in real-time using a $0-4000 \mu \mathrm{S} / \mathrm{cm}$ probe (Hanna Instruments $\mathrm{HI}-99300$ ) sealed into the saltwater side. The probe had a resolution of $1 \mu \mathrm{S} / \mathrm{cm}$ and a manufacturer-reported accuracy of $\pm 2 \%$. The conductivity probe was chosen so as to provide accurate readings to detect small changes in concentration. As a consequence the measurement range was limited, and the maximum salt concentration that could be studied with this system was $1 \mathrm{~g} / \mathrm{L}$. Measurements on stock solutions from $0.1-1.5 \mathrm{~g} / \mathrm{L}$ confirmed that recorded conductivity values were within $\pm 2 \%$. Conductivity of the hot water side was measured periodically to ensure no salt transport across the membrane. Salt concentration was calculated via a pre-determined calibration at $15^{\circ} \mathrm{C}$ :

$E C=1728 X+612$

Where $\mathrm{EC}$ is the conductivity in $\mu \mathrm{S} / \mathrm{cm}$ and $X$ is the salt concentration in $\mathrm{g} / \mathrm{L}$. Measured conductivity values were corrected to $15^{\circ} \mathrm{C}$ using the following equation [28]:

$E C_{15}=E C_{T}[1+0.02(15-T)]$

The salt concentration was calculated for each measurement, and the corresponding uncertainty established based on conductivity values at $\pm 2 \%$. Conductivity was measured within the salt-side header tank at the end of each experiment, and confirmed to be within $2 \%$ of the value taken at the membrane surface. Example experimental data and subsequent salt concentration values are shown in Table 4.

\begin{tabular}{|c|c|c|c|c|c|c|}
\hline \multirow[b]{2}{*}{$\begin{array}{l}\text { Time } \\
\text { min }\end{array}$} & \multirow[b]{2}{*}{$\begin{array}{c}\text { Salt-side } \\
\text { Temp } \\
{ }^{\circ} \mathrm{C}\end{array}$} & \multirow[b]{2}{*}{$\begin{array}{c}\text { Pure water } \\
\text { Temp } \\
{ }^{\circ} \mathrm{C} \\
\end{array}$} & \multicolumn{2}{|c|}{ Salt-side Conductivity } & \multicolumn{2}{|c|}{ Salt Concentration } \\
\hline & & & $\begin{array}{c}\text { Measured } \\
\mu \mathrm{S} / \mathrm{cm}\end{array}$ & $\begin{array}{c}\text { Corrected } \\
\text { to } 15^{\circ} \mathrm{C} \\
\mu \mathrm{S} / \mathrm{cm}\end{array}$ & $\begin{array}{c}\text { From } \\
\text { calibration } \\
\mathrm{g} / \mathrm{L} \\
\end{array}$ & $\begin{array}{c}\text { Uncertainty } \\
\mathrm{g} / \mathrm{L}\end{array}$ \\
\hline 0 & 13.7 & 23.6 & 2390 & 2452 & 1.065 & 0.028 \\
\hline 3 & 13.7 & 23.5 & 2454 & 2518 & 1.103 & 0.029 \\
\hline 7 & 12.8 & 23.7 & 2530 & 2641 & 1.174 & 0.031 \\
\hline
\end{tabular}




\begin{tabular}{|l|l|l|l|l|l|l|}
11 & 12.4 & 23.9 & 2582 & 2716 & 1.218 & 0.031 \\
14 & 12.4 & 23.9 & 2596 & 2731 & 1.226 & 0.032 \\
20 & 12.7 & 24.2 & 2614 & 2734 & 1.228 & 0.032 \\
\hline
\end{tabular}

Table 4 - Example data showing measured conductivity, conductivity corrected to $15^{\circ} \mathrm{C}$, salt concentration and its corresponding uncertainty. $\mathrm{EC}_{15}$ in the header tank after 20 minutes was $2741 \mu \mathrm{S} / \mathrm{cm}$.

Over a period of 20 minutes it can be seen that the salt concentration increases from $1.065 \mathrm{~g} / \mathrm{L}$ to $1.228 \mathrm{~g} / \mathrm{L}$. The average uncertainty in this case is $\pm 0.03 \mathrm{~g} / \mathrm{L}$, and stems from the accuracy of the conductivity measurement. Even at the extremes of the uncertainty range there is still a significant observable increase in salt concentration, which shows that water has transferred from the salt-side to the pure-water side of the membrane during this experiment.

From the raw data the water flux was subsequently calculated over the time period of the experiment based on the initial volume on the salt-water side and the measured change in concentration. Max/min values were then established based on the measurement uncertainty. This is shown in Table 5 for a number of different experimental conditions, including control tests with no temperature gradient.

\begin{tabular}{|c|c|c|c|c|c|}
\hline \multirow[b]{2}{*}{$\begin{array}{c}\Delta \mathrm{T}_{\text {avg }} \\
{ }^{\circ} \mathrm{C}\end{array}$} & \multirow[b]{2}{*}{$\begin{array}{c}\mathrm{NaCl} \\
\text { conc. } \\
\mathrm{g} / \mathrm{L}\end{array}$} & \multirow[b]{2}{*}{$\begin{array}{l}\text { Total } \\
\text { time } \\
\text { min }\end{array}$} & \multicolumn{3}{|c|}{ Water flux } \\
\hline & & & $\begin{array}{l}\text { Measured } \\
\times 10^{-3} \mathrm{~kg} / \mathrm{m}^{2} . \mathrm{s}\end{array}$ & $\begin{array}{c}\text { Max } \\
\times 10^{-3} \mathrm{~kg} / \mathrm{m}^{2} . \mathrm{s}\end{array}$ & $\begin{array}{c}\text { Min } \\
\times 10^{-3} \mathrm{~kg} / \mathrm{m}^{2} . \mathrm{s}\end{array}$ \\
\hline 0 & 1 & 3250 & -0.276 & -0.111 & -0.542 \\
\hline 1.5 & 1 & 35 & 18.2 & 44.6 & -4.32 \\
\hline 2.5 & 1 & 20 & 27.4 & 50.1 & 8.86 \\
\hline 10.8 & 1 & 20 & 113 & 145 & 67.2 \\
\hline 0 & 0.35 & 5760 & -0.069 & 0.111 & -0.267 \\
\hline 1.5 & 0.35 & 120 & 15.6 & 31.1 & -0.925 \\
\hline 9.3 & 0.35 & 28 & 65.4 & 80.0 & 50.8 \\
\hline
\end{tabular}

Table 5 - Experimental water flux for different temperature gradients and water salinities.

The validation tests carried out with no temperature gradient were left for a period of 3-4 days. In each case it was observed that the salt-water side of the membrane was becoming diluted over time due to the expected osmotic action. This data is shown in Table 5 for cases when $\Delta T=0$, and water fluxes are assigned a negative sign to denote water transport from the pure water side to the salt water side. When the pure water side is heated the salt concentration on the opposing side of the membrane was observed to increase, with observable differences being apparent in as little as 10 minutes. The increase in salt concentration was due to water moving across the membrane from the 
salt water side to the pure water side, i.e. reverse osmosis. As expected, the water flux increased with an increase in temperature gradient, and decreased with increasing salt concentration. The inherent uncertainty in conductivity probe measurements was accounted for by calculating the maximum and minimum flux based on $\pm 2 \%$ of the conductivity reading, and these flux values are shown in Table 5 . At the extremes of uncertainty, the $1 \mathrm{~g} / \mathrm{L}$ salt concentrations in the control test with no temperature gradient gave a negative flux (osmosis), and the experiments with a temperature gradient of 2.5 and $10.8^{\circ} \mathrm{C}$ gave positive fluxes (reverse osmosis). At $1 \mathrm{~g} / \mathrm{L}$ and $1.5^{\circ} \mathrm{C}$ the uncertainty means that either osmosis or reverse osmosis could have occurred. For the $0.35 \mathrm{~g} / \mathrm{L}$ experiments the $9.3^{\circ} \mathrm{C}$ temperature gradient resulted in reverse osmosis, but the uncertainty is too high to confirm the direction of water flux for the control and the $1.5^{\circ} \mathrm{C}$ temperature differential.

Despite the inherent uncertainty with the measurement device used, the experiments and data in Table 5 are sufficient to confirm that reverse osmosis can indeed take place at atmospheric pressure when a temperature difference is maintained across the membrane. It is possible to go beyond this qualitative conclusion and compare the outcomes more quantitatively. Equation 13 shows how pressure, temperature and composition terms all add to produce the net chemical potential gradient for mass transfer. An equivalent pressure can therefore be calculated for each combination of $\Delta T$ and salt concentration. When $\Delta T=0$ this pressure equivalent is equal to the osmotic pressure for the salt concentration used. With an equivalent pressure it is then possible to establish the membrane permeability from the measured flux and the cross-sectional area. Table 6 shows the equivalent pressure and permeability for each of the experiments carried out, as well as the permeability range arising from the uncertainty in water flux measurements.

\begin{tabular}{|c|c|c|c|c|c|}
\hline \multirow[b]{2}{*}{$\begin{array}{c}\Delta \mathrm{T}_{\text {avg }} \\
{ }^{\circ} \mathrm{C}\end{array}$} & \multirow[b]{2}{*}{$\begin{array}{c}\mathrm{NaCl} \\
\text { conc. } \\
\mathrm{g} / \mathrm{L}\end{array}$} & \multirow[b]{2}{*}{$\begin{array}{c}\text { Equivalent } \\
\text { Pressure } \\
\text { bar }\end{array}$} & \multicolumn{3}{|c|}{ Equivalent Permeability } \\
\hline & & & $\begin{array}{l}\text { Measured } \\
1 / \mathrm{m}^{2} \text {.h.bar }\end{array}$ & $\begin{array}{c}\text { Max } \\
\text { I/m².h.bar }\end{array}$ & $\begin{array}{c}\text { Min } \\
\mathrm{l} / \mathrm{m}^{2} \cdot h \cdot \text { bar }\end{array}$ \\
\hline 0 & 1 & -0.72 & 0.895 & 1.758 & 0.360 \\
\hline 1.5 & 1 & 57.5 & 1.139 & 2.791 & -0.270 \\
\hline 2.5 & 1 & 103.0 & 0.958 & 1.752 & 0.310 \\
\hline 10.8 & 1 & 418.5 & 0.973 & 1.249 & 0.579 \\
\hline 0 & 0.35 & -0.25 & 0.994 & 3.846 & -1.598 \\
\hline 1.5 & 0.35 & 58.0 & 0.968 & 1.930 & -0.009 \\
\hline 9.3 & 0.35 & 360.8 & 0.653 & 0.798 & 0.507 \\
\hline
\end{tabular}

Table 6 - Equivalent Permeability values based on the measured flux and the uncertainty range. Equivalent pressure calculated from Equation 15. 
The equivalent pressure varies from -0.72 bar to +418.5 bar, the negative sign denoting a pressure gradient from pure water to salt water for the cases where no temperature gradient was employed. Despite such a large range in pressure equivalence, it is shown in Table 6 that the measured permeability values are all very similar, ranging from $0.653-1.14 \mathrm{l} / \mathrm{m}^{2}$.h.bar. These values are based on the measured fluxes reported in Table 5. Uncertainty due to the resolution of the conductivity probe has been used to calculate the likely upper and lower permeability limits for each set of experimental conditions, as shown in Table 6. The measured values, and the corresponding uncertainty can be compared with the manufacturer-quoted range for this particular membrane material. In conventional reverse osmosis the membrane used in this study has a reported permeability of 17-24 gfd for seawater at $800 \mathrm{psi}$ [29]. The osmotic pressure in this case is around 25 bar (363 psi), so the pressure driving force for water transport is 437 psi. Converting to the same permeability units used within Table 6 gives a permeability range of $0.962-1.358 \mathrm{l} / \mathrm{m}^{2}$.h.bar. Figure 4 shows how the experimental results and associated uncertainty compare with the manufacturer-quoted range for membrane permeability.

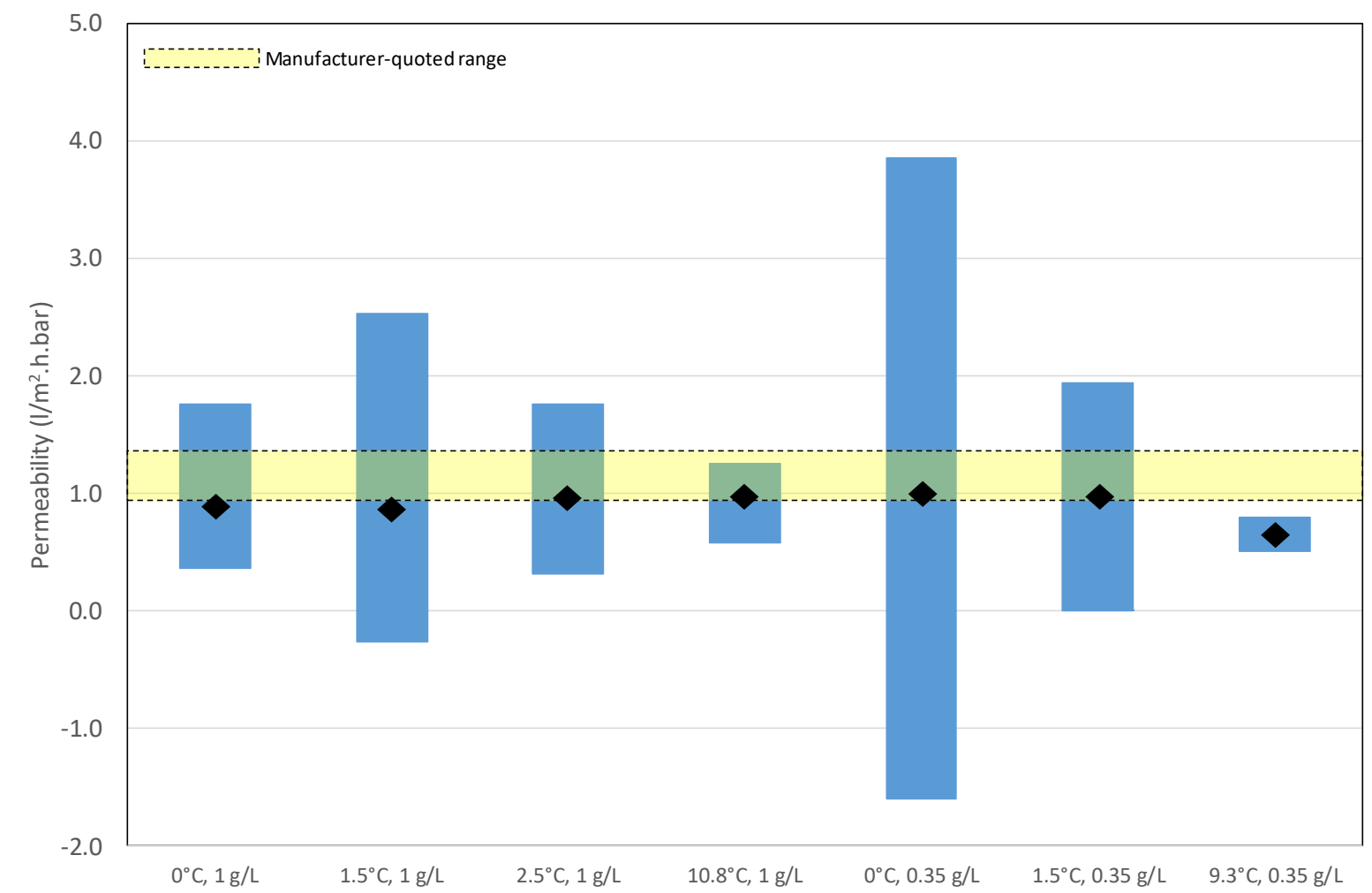

Figure 4 - Permeability (points) and uncertainty range (bars) for different experimental conditions, and compared with manufacturer-quoted values

The measured permeability values are all at or just below the lower-end of the permeability range quoted by the manufacturer, this despite the equivalent pressure varying from -0.72 bar to +418.5 bar. The degree of uncertainty from the experiments is dependent upon the salt concentration and 
the temperature difference. In general the uncertainty is higher when the temperature difference is low, and this is due to the relatively small change in concentration observed over the duration of the experiments. When larger temperature gradients were studied the effective driving force is higher, leading to larger changes in concentration relative to the measurement uncertainty. In all but one of the conditions studied the uncertainty due to concentration measurement falls within the manufacturer-quoted permeability range.

Whilst the uncertainty encountered in the experimental study is far from ideal, the data from the simple experimental setup does nonetheless show close agreement with the manufacturer-quoted values for the membrane. The inference from Figure 4 is that changes in temperature gradient and salt concentration can be rationalised with the newly-developed thermodynamic model to give very close agreement with permeability range used for traditional reverse osmosis processes. No stirring was used on the salt-water side of the experimental apparatus, so concentration polarisation will have occurred, which in both the forward and reverse osmosis cases will lead to a reduction in the driving force and consequently the magnitude of the water flux. Adjusting for polarisation effects will result in an increase in all the measured permeability values.

\section{Conclusions and Implications}

This paper reports the first step in the identification and development of a new concept for reverse osmosis. A theoretical approach was identified based on the use of a small temperature gradient, and this was validated by experimental measurements at a range of temperature differentials and salinity. Water fluxes obtained with varying temperature and salt concentration closely matched with the permeability of the membrane as stated by the manufacturer. The concept therefore has the potential to allow reverse osmosis to be carried out without the need for high pressure pumps and pressure/energy recovery systems. Energy requirements have not been assessed empirically in this case, but the theoretical minimum can be lower than $2.0 \mathrm{kWh} / \mathrm{m}^{3}$ if heat losses can be minimised beyond the heat flow needed to sustain mass transfer. Membranes have traditionally been engineered to sustain a pressure difference across the active layer, whereas in this case there is no pressure gradient. This opens up opportunities to use different, and potentially lower-cost membrane materials and module configurations. If the capital cost can be reduced significantly then smaller-scale reverse osmosis systems could be within reach, ones that do not need to rely so heavily on economies of scale.

With the concept validated in this study there is a great deal of further work that is needed to understand the energy requirements and overall cost implications compared to traditional reverse 
osmosis. The suitability of a range of membrane materials and heating techniques to sustain the required thermal gradient needs to be assessed. Options include microwave, induction, ohmic and convective heating, all of which have the potential to create the temperature gradients identified in this work. The membranes themselves will need to be engineered using different criteria to conventional reverse osmosis. Thermal conductivity will be key to the viability of this process, so as to maintain the temperature gradient without incurring significant heat losses. If heat losses can be kept to a minimum then on energy use alone this concept presents an attractive alternative to conventional pressure-driven desalination. Conductive losses across the membrane will be restricted due to the small temperature gradients needed for mass transfer, but for very thin active layers will provide very low resistance to heat transfer and could result in energy requirements that are considerably higher than the minimum. It is likely that novel composites are required to fulfil this requirement, and these would need to be fabricated for suitable high surface-area housings for any industrial scale system. Progressing this concept cannot be achieved with the batch apparatus used in this study, but instead requires the construction of a continuous system to enable and evaluate different heating methods, test a range of membrane materials and identify the heat losses and subsequent overall energy requirements. The capital costs of the heating equipment can then be compared with the high pressure hardware used conventionally, at which point the true opportunities and costs of the temperature-gradient concept can be fully understood.

\section{Nomenclature}

\begin{tabular}{|l|l|}
\hline$a$ & activity \\
\hline$c_{p}$ & specific heat capacity \\
\hline$f$ & fugacity \\
\hline$\mu$ & chemical potential \\
\hline$P$ & pressure \\
\hline$\Pi$ & osmotic pressure \\
\hline$R$ & universal gas constant \\
\hline$s$ & entropy \\
\hline$T$ & temperature \\
\hline$v$ & molar volume \\
\hline$x$ & mole fraction \\
\hline
\end{tabular}




\section{References}

1 E. Hameeteman. Future Water (In)Security. Global Water Institute, 2013 https://img1.wsimg.com/blobby/go/27b53d18-6069-45f7-a1bdd5a48bc80322/downloads/1c2meuvon 105010.pdf Last accessed February 2019.

2 United Nations world water development report 4: managing water under uncertainty and risk. Foreword by I.G. Bokova. http://www.unesco.org/new/en/naturalsciences/environment/water/wwap/wwdr/wwdr4-2012/ Last accessed February 2019.

3 C. Jacob, Desalination, 205, 2007, 47-52

4 L.F. Greenlee et al., Water Res. 43, 2009, 2317-2348

5 K. Zotalis, et al., Water, 6, 2014, 1134-1150

6 W.J. Koros and R.P. Lively, AIChE J. 58, 2012, 2624-2633

7 M. Mulder, Basic principles of membrane technology, 2nd Ed. Kluwer, Netherlands, 2000.

8 K. P. Lee et al., J Membr Sci, 370, 2011, 1-22

9 P. Geisler et al., Desalination 122, 1999, 151-156

10 C. Fritzmann et al., Desalination, 216, 2007, 1-76

11 N. Hilal et al., Desalination, 273, 2011, 23-35.

12. J.H. Redondo, Desalination, 138, 2001, 231-236.

13 M.L. Lind, et al., Langmuir, 25, 2009, 10139-10145

14 D. Rana and T. Matsuura, Chem. Rev., 110, 2010, 2448-2471

15 J.-M. Laine, Design \& Operation Considerations: Two Large-Scale Case Studies, in, Suez Environment, 2009.

16 M. Faigon, Filtration and Separation, 53, 2016, 29-31.

17 R. Sheikholeslami, Desalination, 248, 2009, 218-224

18 B. Van der Bruggen, P. Luis Rev, Chem Eng, 31, 2015, 1-12

19 S. Zhao et al., J Membr Sci, 396, 2012, 1-21

20 T.-S. Chung, Separ Purif Tech, 156, 2015, 856-860

21 R. K. McGovern and J. H. Lienhard V, J Membr Sci, 469, 2014, 245-250.

22 S. H. Schneider, Encyclopedia of Climate and Weather (Oxford Univ. Press, 1996).

23 B. Gido et al., Atmosphere Res., 182, 2016, 156-162.

24 C.S. Lee et al. Chemical Engineering Science 149, 2016, 97-103.

25 W.Z. Black and J.G. Hartley. Thermodynamics. HarperCollins, New York 1996.

26 Thermodynamic and Transport Properties of Fluids. G.F.C. Rogers and Y.R. Mayhew. Blackwell, Oxford, 1995

27 N. Hubert et al. Thermochimica Acta 294 (1997) 157-163

28 M. Hayashi, Environmental Monitoring and Assessment 96, 121-130, 2004

29 https://www.sterlitech.com/dow-filmtec-flat-sheet-membrane-sw30hr-pa-tfc-ro-cf016-5pk.html. Last accessed February 2019. 